\title{
pH-Controlled Hydrothermal Synthesis of Submicrometer-Sized CdS Spheres with Uniform Size Distribution
}

\author{
Myunghan Lee, ${ }^{\dagger}$ Sungjune Han, ${ }^{\dagger}$ and Young Jin Jeon ${ }^{*}$ \\ Department of Applied Chemistry, College of Natural Sciences, Konkuk University, Chungju 380-701, Korea \\ *E-mail: jeonyj@kku.ac.kr \\ ${ }^{\dagger}$ Department of Advanced Technology Fusion, Konkuk University, Seoul 143-701, Korea \\ Received September 2, 2010, Accepted September 24, 2010
}

Key Words: Cadmium sulfide, pH control, Hydrothermal reaction, Morphological control, L-Cysteine

For several decades, intensive research has been carried out on the morphological control of semiconductor nanomaterials. This is because semiconductor materials have various unique properties, which can be attributed to their shape and size. ${ }^{1-3}$ In particular, many researchers have carried out in-depth studies on CdS because it has numerous applications; for example, $\mathrm{CdS}$ can be used as a photocatalyst ${ }^{4}$ as well as in solar cells ${ }^{5}$ and light-emitting diodes. ${ }^{6} \mathrm{CdS}$ has been synthesized by solid-state methods, ${ }^{7,8}$ solvothermal methods, ${ }^{9,10}$ precipitation, ${ }^{11}$ microwave-assisted solvothermal method, ${ }^{12}$ and liquid-crystal templating, ${ }^{13}$ and calcinations of Cd-thiolates. ${ }^{14}$ Among these, solvothermal methods involving the use of Cd(II) ions as the metal source, various sulfur-containing ligands as sulfur sources, and shape-directing agents have been studied extensively. L-Cysteine has been employed as the sulfur source in many solvothermal syntheses. ${ }^{9,10}$ This amino acid has three deprotonation sites, i.e., carboxylic acid, amine, and thiol sites, which are potential metal-ion-binding sites. It is already known that Cd(II)-L-cysteine complexes in an aqueous solution indicate the formation of Cd-S and Cd-O bonds but not the coordination of the ammonium group in L-cysteine with the $\mathrm{Cd}(\mathrm{II})$ ion. ${ }^{15,16}$ By controlling the deprotonation of ammonium group of Cd(II)-L-cysteine complex, one can easily control the intermolecular interactions between the complexes. Qian and coworkers successfully synthesized three-dimensional (3D) and one-dimensional (1D) CdS nanostructures by carrying out reactions between $\mathrm{Cd}(\mathrm{II})$ and L-cysteine in a binary solution comprising ethylenediamine and water. ${ }^{9}$ They reported that solvent composition is crucial in determining the $\mathrm{CdS}$ morphology and that ethylenediamine probably acts as a shape-directing agent that causes passivation of the CdS nanostructures. Further, the CdS particles obtained had irregular shapes when pure water was used as the solvent.

Herein, we report the effect of $\mathrm{pH}$ on the morphology of the submicrometer-sized CdS particles obtained in a hydrothermal reaction. We could control the $\mathrm{pH}$ of an aqueous solution containing $\mathrm{Cd}(\mathrm{II})$ ions and L-cysteine by adding $\mathrm{NaOH}$. The results of the present study may shed light on the mechanism underlying the formation of submicron-sized $\mathrm{CdS}$ particles from $\mathrm{Cd}(\mathrm{II})$ ions and L-cysteine under hydrothermal conditions.

\section{Experimental Section}

All the chemicals were of analytical grade and were used as-received without further purification. Distilled water was purified by a Millipore Milli-Q water purification system (Branstead, USA). IR spectra were recorded using a MIDAC M series spectrometer. Powder X-ray diffraction (XRD) spectra were recorded at $40 \mathrm{kV}$ and $35 \mathrm{~mA}$ using a Philips X'pert-MPD diffractometer (Philips Analytical, Netherlands); $\mathrm{Cu} \mathrm{K} \alpha$ radiation was used as the source $(\lambda=1.5418 \AA)$. Scanning electron microscopy (SEM) and energy-dispersive X-ray spectroscopy (EDX) analyses were performed using a HITACHI S-3000N system and a JEOL JSM 6700 SEM spectrometer, respectively. Raman spectra were obtained by using an inVia Raman spectrometer (Renishaw, USA); the excitation wavelength was $488 \mathrm{~nm}$.

Preparation of CdS samples. Aqueous solutions of $\mathrm{Cd}\left(\mathrm{NO}_{3}\right)_{2}$ $(10 \mathrm{mM}, 20 \mathrm{~mL})$ and L-cysteine $(100 \mathrm{mM}, 20 \mathrm{~mL})$ were mixed in a vessel (final conc.: $\mathrm{Cd}(\mathrm{II}), 5 \mathrm{mM}$; L-cysteine, $50 \mathrm{mM}$ ) and vortexed for $10 \mathrm{~min}$. Then, $\mathrm{NaOH}(1.0 \mathrm{M})$ solution was added under constant magnetic stirring to adjust the $\mathrm{pH}$ of the solution to the desired value $(3,7$, or 12$)$. The change in the solution $\mathrm{pH}$ was monitored by using a $\mathrm{pH}$ meter. Subsequently, the solution was transferred to a hydrothermal reactor, heated to $150{ }^{\circ} \mathrm{C}$, and maintained at this temperature for 3 days. The resulting products were washed several times with distilled water and ethanol and dried in a desiccator.

\section{Results and Discussion}

The effect of $\mathrm{pH}$ on the formation of submicrometer-sized $\mathrm{CdS}$ particles under hydrothermal conditions from a solution containing Cd(II) and L-cysteine (molar ratio 1:10) was investigated. For this purpose, the $\mathrm{pH}$ of the solution was adjusted by the dropwise addition of $\mathrm{NaOH}(1.0 \mathrm{M})$ solution under constant magnetic stirring. The $\mathrm{pH}$ change was carefully monitored with the help of a $\mathrm{pH}$ meter. The solution prepared in the abovementioned manner was transferred to a hydrothermal reactor and heated at $150{ }^{\circ} \mathrm{C}$ for 3 days. The products were washed several times with distilled water and ethanol and dried in a desiccator. Figure 1 shows the SEM images of the CdS particles obtained at $\mathrm{pH} 3,7$, and 12 . The $\mathrm{CdS}$ particles prepared at $\mathrm{pH} 3$ and 7 formed large irregular aggregates, as shown in Figures 1a and $1 \mathrm{~b}$, respectively. The formation of CdS particles with such irregular morphology was reported by Qian and coworkers. ${ }^{9}$ On the other hand, the product prepared at $\mathrm{pH} 12$ comprised uniform, spherical submicrometer-sized particles, as shown in Figure 1c. The size distribution of the particles was around $403 \pm 54 \mathrm{~nm}$. Interestingly, this striking difference in the appa- 

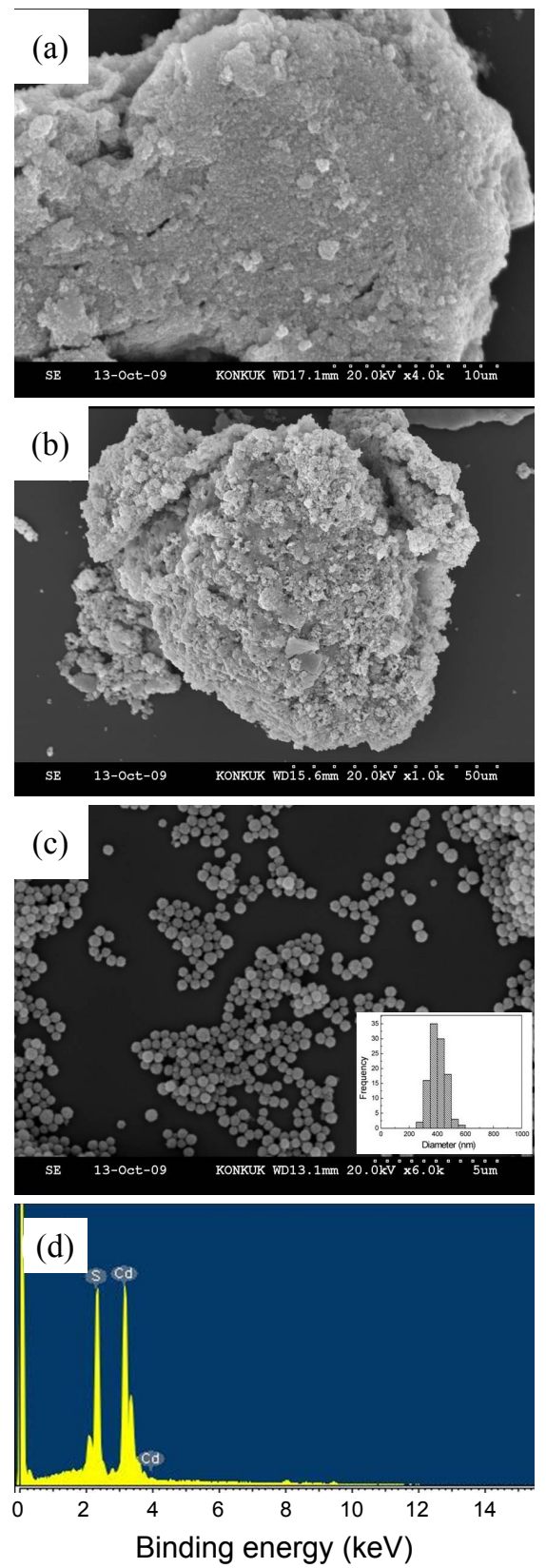

Figure 1. SEM images of the samples prepared under different $\mathrm{pH}$ conditions: (a) $\mathrm{pH}=3.0$; (b) $\mathrm{pH}=7.0$; (c) $\mathrm{pH}=12.0$, and (d) $\mathrm{EDX}$ spectrum of (c). In all cases, the molar ratio of $\mathrm{Cd}\left(\mathrm{NO}_{3}\right)_{2} / \mathrm{L}$-cysteine $=$ $1: 10$, with hydrothermal reaction for $3 \mathrm{~d}$ at $150{ }^{\circ} \mathrm{C}$.

rent morphologies of the products was only due to the difference in the solution $\mathrm{pH}$, as all the other reaction conditions were the same in the three cases. At this point, we mention that the molar ratio between $\mathrm{Cd}^{2+}$ and L-cysteine is also important in the hydrothermal formation of CdS particles. In a preliminary experiment, the morphology of CdS synthesized with a lower molar ratio (i.e. $\mathrm{Cd}^{2+} / \mathrm{L}$-cysteine $=1: 2$ at $\mathrm{pH} 12$ ) indicates severe irregular aggregation of $\mathrm{CdS}$ particles. Along this line, we maintained the molar ratio $\mathrm{Cd}^{2+}: \mathrm{L}$-cysteine $(1: 10)$.

We first consider the various modes of complex formation between $\mathrm{Cd}(\mathrm{II})$ ions and L-cysteine in aqueous solution. While there are several suggested complex formation mechanisms,

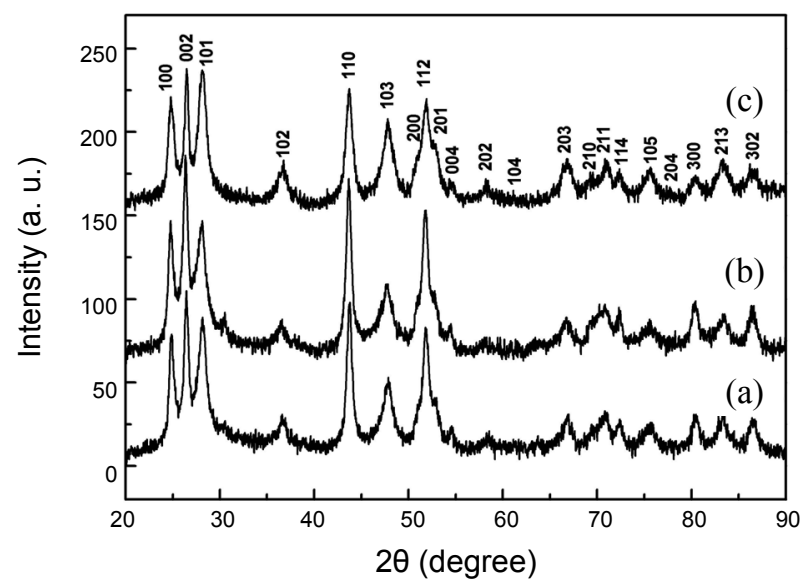

Figure 2. XRD patterns of CdS synthesized at (a) $\mathrm{pH} 3$, (b) $\mathrm{pH} 7$, and (c) $\mathrm{pH} 12$

the commonly accepted ones are those involving the formation of a polymeric chain and 3:4 complexes $\left(\mathrm{Cd}_{n}(\mathrm{~L}-\mathrm{Cys})_{\mathrm{n}}\right.$ and $\mathrm{Cd}_{3}$ (L-Cys $\left.)_{4}\right){ }^{15-17}$ The similarity between the two complex models is that they both indicate the formation of Cd-S and $\mathrm{Cd}-\mathrm{O}$ bonds but not the coordination of the ammonium group in L-cysteine with the Cd(II) ion. ${ }^{15,16}$ The possible reason for the marked difference between the morphologies of the CdS particles synthesized at $\mathrm{pH} 3,7$, and 12 is the ammonium-amine conversion when the solution $\mathrm{pH}$ is increased to 12 , which is approximately $2 \mathrm{pH}$ units higher than the $\mathrm{p} K_{\mathrm{a}}$ value of the ammonium group $\left(\alpha-\mathrm{NH}_{3}{ }^{+}\right)$in L-cysteine $\left(\mathrm{p} K_{\mathrm{a}}\right.$ of $\left.\alpha-\mathrm{NH}_{3}{ }^{+}=10.28\right) .{ }^{18}$ This conversion probably plays an important role in the intermolecular interactions between $\mathrm{Cd}(\mathrm{II}) / \mathrm{L}$-cysteine complexes and influences the hydrophobicity of the complexes in aqueous solution. At elevated temperatures, the complex undergoes thermal degradation, and the thiol groups in L-cysteine (sulfur source) are hydrolyzed. Then, spherical submicron-sized CdS particles are formed.

The results of EDX analysis reveal that the $\mathrm{Cd} / \mathrm{S}$ ratio in the $\mathrm{CdS}$ particles obtained at $\mathrm{pH} 12$ is 50.6:49.4, indicating that $\mathrm{Cd}$ and $\mathrm{S}$ are nearly in 1:1 molar ratio (Figure 1d). Similar EDX results are observed for the products obtained at $\mathrm{pH} 3$ and 7. The products obtained under the three different $\mathrm{pH}$ conditions used in this study are CdS nanostructures with a hexagonal würzite structure (JCPDS No. 41-1049), as confirmed by the observed XRD patterns (Figure 2). No impurity peaks are found in the XRD spectra, and hence, the as-synthesized particles are confirmed to be pure. The XRD peaks corresponding to the $\mathrm{CdS}$ nanoparticles are broader than those of bulk $\mathrm{CdS}$, indicating that the obtained particles are smaller than expected. The crystallite size is calculated from the XRD patterns by using the Debye-Scherrer equation: ${ }^{19}$

$$
D=0.9 \lambda / \mathrm{B} \cos \theta
$$

where $D$ is the coherence length of the crystallite; $\mathrm{B}$, the fullwidth at half-maximum (FWHM) of the peak; $\lambda$, the wavelength of the X-ray source (1.5418 $\AA$ ); and $\theta$, the angle of diffraction. The calculated coherence lengths of the crystallites are 16.8 (pH 3), 14.8 ( $\mathrm{pH} \mathrm{7)}$, and $12.2 \mathrm{~nm}(\mathrm{pH} \mathrm{12)}$. From these results, 


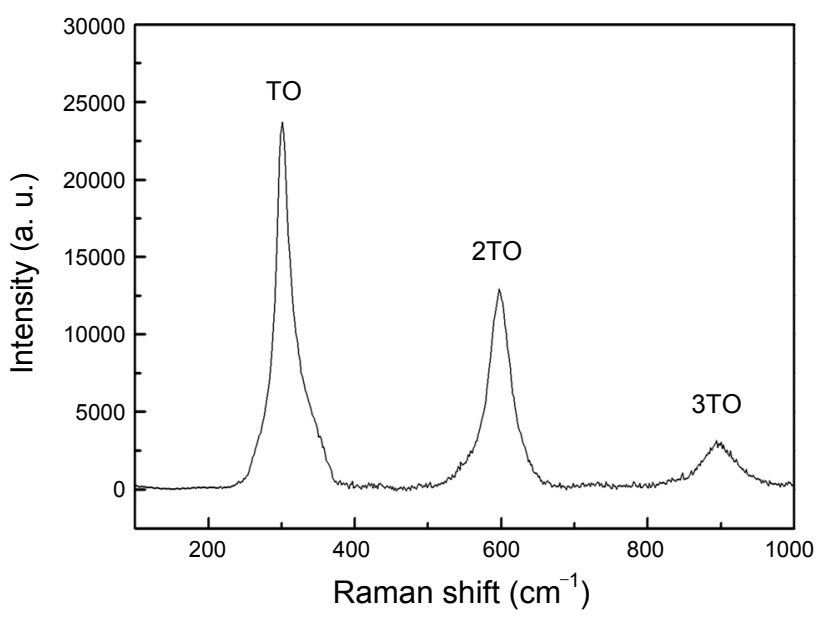

Figure 3. Raman spectrum of CdS synthesized at pH 12.
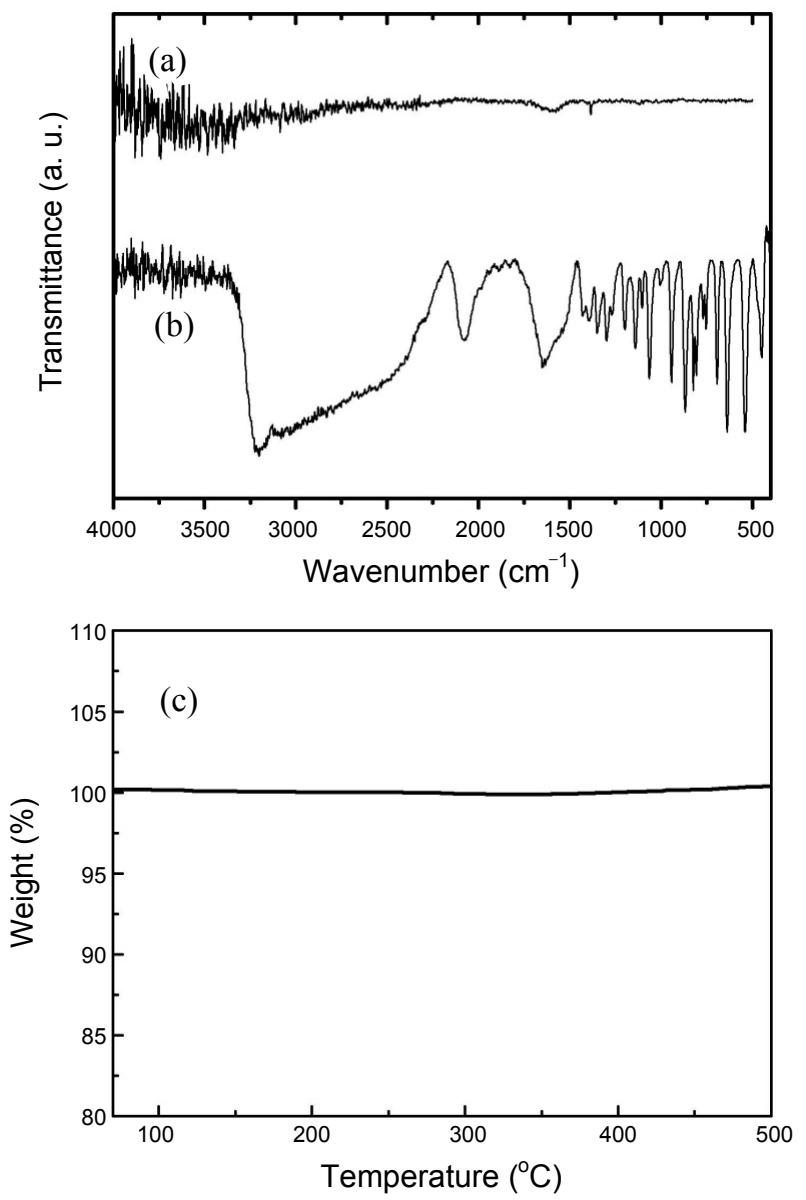

Figure 4. IR spectra of (a) CdS and (b) L-cysteine, and (c) TGA scan of CdS synthesized at $\mathrm{pH} 12$.

we can conclude that although their apparent morphologies are different with each other, they are all composed of CdS particles whose sizes are over $10 \mathrm{~nm}$. In other words, submicrometersized spherical CdS structures are formed by self-assembling of the CdS nanoparticles and are thus polycrystalline. Interestingly, the coherence lengths of the crystallites decrease with an increase in the solution $\mathrm{pH}$, as has been reported in a previous study. $^{20}$

As can be seen in Figure 3, the Raman spectrum of the CdS particles synthesized at $\mathrm{pH} 12$ shows three bands at $300 \mathrm{~cm}^{-1}$, $597 \mathrm{~cm}^{-1}$, and $894 \mathrm{~cm}^{-1}$, which correspond to the first-, second-, and third-order transverse optical (TO) phonon modes of CdS, respectively. ${ }^{14}$ The peaks appear at lower frequencies as compared to those of bulk CdS, indicating that the submicrometersized CdS particles are composed of CdS nanoparticles. This reconfirms the results of the XRD experiments.

Figure 4 shows the IR spectra of L-cysteine and CdS synthesized at $\mathrm{pH} 12$ and the results of thermogravimetric analysis (TGA). From the IR spectra, it was apparent that L-cysteine did not cause passivation of the surface of the $\mathrm{CdS}$ nanoparticles. Surprisingly, even when the amount of L-cysteine added to the reaction solution was 10 times that of $\mathrm{Cd}(\mathrm{II})$, there was no apparent passivation of the ligands on the surface of CdS nanostructures, as shown in Figures $4 \mathrm{a}$ and $4 \mathrm{~b}$. The characteristic IR peaks of L-cysteine almost disappeared after the reaction. In addition, the TGA results further confirmed that the $\mathrm{CdS}$ nanostructures were bare, as shown in Figure $4 \mathrm{~b}$. Above $500{ }^{\circ} \mathrm{C}$, the temperature regime where organic compounds are generally pyrolyzed, the TGA curve does not indicate any notable weight loss.

\section{Conclusion}

We synthesized spherical CdS nanostructures with different morphologies from a solution containing $\mathrm{Cd}$ (II) ions and L-cysteine, by simply adjusting the solution $\mathrm{pH}$ using $\mathrm{NaOH}$ under hydrothermal conditions. At $\mathrm{pH} 3$ and 7, the $\mathrm{CdS}$ particles were strongly aggregated, while at $\mathrm{pH} 12$, spherical CdS nanoparticles were formed. This was probably due to the change in the intermolecular interactions in the Cd-(L-Cys) complexes and the solubility of the complexes. The change in the solubility could be attributed to the conversion of the ammonium group of L-cysteine into an amine in aqueous solution. The results of the present study might help in elucidating the mechanism underlying the formation of CdS from $\mathrm{Cd}(\mathrm{II})$ ions and L-cysteine under hydrothermal conditions. The synthesis method proposed herein is convenient and environmentally benign and can be used in a variety of applications in the future.

Acknowledgments. This work was supported by Konkuk University in 2010.

\section{References and Notes}

1. Weller, H. Adv. Mater. 1993, 5, 88 .

2. Alivisatos, A. P. Science 1996, 271, 933.

3. Eychmuller, W. J. Phys. Chem. B 2000, 104, 6514.

4. Hirai, T.; Bando, Y.; Komasawa, I. J. Phys. Chem. B 2002, 106, 8967.

5. Matsune, K.; Oda, H.; Toyama, T.; Okamoto, H.; Kudriavysevand, Y.; Asomoza, R. Sol. Energ. Mat. Sol. C 2006, 90, 3108.

6. Zhao, J.; Bardecker, J. A.; Munro, A. M.; Liu, M. S.; Niu, Y.; Ding, I. K.; Luo, J.; Chen, B.; Jen, A. K.; Ginger, D. S. Nano. Lett. 2006, 6, 463.

7. Williams, R.; Yocom, P. N.; Stofko, F. S. J. Coll. Interf. Sci. 1985, 106, 388. 
8. Thompson, A. H. Mater. Res. Bull. 1975, 10, 915.

9. Xiong, S.; Xi, B.; Wang, C.; Zou, G.; Fei, L.; Wang, W.; Qian, Y. Chem. Eur. J. 2007, 13, 3076.

10. Gai, H.; Wu, Y.; Wu, L.; Wang, Z.; Shi, Y.; Jing, M.; Zou, K. Appl. Phys. A 2008, A91, 69.

11. Li, Y.; Liao, H.; Ding, Y.; Fan, Y.; Zhang, Y.; Qian, Y. Inorg. Chem. 1999, 38, 1382.

12. Murugan, A. V.; Kale, B. B.; Kulkarni, A. V.; Kunde, L. B.; Saaminathan, V. J. Mater. Sci. - Mater. Electron. 2005, 16, 295.

13. Im, S.-J.; Chae, W.-S.; Lee, S.-W.; Kim, Y.-R. Mater. Res. Bull. 2006, 41, 899 .
14. Han, S.; Lee, M.; Jeon, Y. J. Bull. Korean Chem. Soc. 2010, 31, 1091.

15. Barrie, P. J.; Gyani, A.; Montevalli, M.; O'Brien, P. Inorg. Chem. 1993, 32, 3862.

16. Shindo, H.; Brown, T. L. J. Am. Chem. Soc. 1965, 87, 1904.

17. Jalilehvand, F.; Leung, B. O.; Mah, V. Inorg. Chem. 2009, 48, 5758.

18. Lehninger, A. L.; Nelson, D. L.; Cox, M. M. Principles of Biochemistry, 2nd ed.; Worth Publishers: New York, 1993.

19. Nanda, J.; Sapra, S.; Chandrasekharan, N.; Hodes, G. Chem. Mater. 2002, 12, 1018.

20. Hayashi, J.; Nishi, M.; Wanaka, M. Chem. Lett. 2009, 38, 450. 